Original Paper (Invited)

\title{
Steady and unsteady flow computation in an elbow draft tube with experimental validation
}

\author{
Thi C. Vu ${ }^{1}$, Christophe Devals ${ }^{2}$, Ying Zhang ${ }^{2}$, Bernd Nennemann ${ }^{1}$ and François Guibault ${ }^{2}$ \\ ${ }^{1}$ Andritz-Hydro Ltd. \\ 6100 TransCanada highway Pointe Claire, QC, H9R 1B9, Canada, \\ thi.vu@andritz.com, bernd.nennemann@andritz.com \\ ${ }^{2}$ Department of Computer and Software Engineering, École Polytechnique de Montréal \\ CP 6079, succ. Centre-Ville, Montréal, QC, H3C 3A7, Canada, \\ christophe.devals@polymtl.ca,ying.zhang@polymtl.ca, francois.guibault@polymtl.ca
}

\begin{abstract}
Steady state computations are routinely used by design engineers to evaluate and compare losses in hydraulic components. In the case of the draft tube diffuser, however, experiments have shown that while a significant number of operating conditions can adequately be evaluated using steady state computations, a few operating conditions require unsteady simulations to accurately evaluate losses. This paper presents a study that assesses the predictive capacity of a combination of steady and unsteady RANS numerical computations to predict draft tube losses over the complete range of operation of a Francis turbine. For the prediction of the draft tube performance using k- $\varepsilon$ turbulence model, a methodology has been proposed to average global performance indicators of steady flow computations such as the pressure recovery factor over an adequate number of periods to obtain correct results. The methodology will be validated using two distinct flow solvers, CFX and OpenFOAM, and through a systematic comparison with experimental results obtained on the FLINDT model draft tube.
\end{abstract}

Keywords: Hydraulic turbine, draft tube, steady flow simulation, unsteady flow simulation.

\section{Introduction}

In an industrial setting, accurate numerical prediction of the performance of a draft tube over its complete range of operation must be performed as efficiently as possible. The choice of mesh density, turbulence model and time accuracy must therefore be balanced carefully against the need of obtaining results in a timely fashion. This paper aims to validate standardized RANS CFD simulations for the global performance prediction of a draft tube through comparison with experiments carried out at the LMH laboratory in Switzerland, as part of the FLINDT project [1].

Recently, several studies have been devoted to the accurate prediction of unsteady pressure fluctuations inside the draft tube, associated with the precession of the vortex rope. To reach an adequate level of accuracy, these calculations require advanced turbulence modelling and unsteady flow simulations on meshes comprising several million nodes [2, 3, 4]. In design mode however, global performance characteristics must be obtained rapidly and these types of detailed simulations cannot be performed routinely. Efforts must therefore be devoted to the validation of computational schemes and simplifying approaches that allow reaching adequate levels of precision in a reasonable time and using relatively modest computational resources. The present study is thus aimed at providing design engineers with faster, more reliable analysis tools that can be readily integrated into their design process.

\section{Problem statement}

Steady state flow simulations are often totally adequate to predict global performance of well behaved draft tubes operated at or close to the best efficiency point of the turbine. However, when a badly designed draft tube is present, or when operating conditions become less favorable, convergence problems are observed, which often translate into an oscillatory behavior of the individual residual history of the main variables of the governing equations. These high residuals prevent the solution process from reaching global convergence, and global quantities, such as the pressure recovery factor, from reaching a stable value. Typical convergence histories for a stable and a periodic convergence are illustrated in Fig. 1.

Accepted for publication December 16, 2010: Paper number O10047S

Corresponding author: Thi C. Vu, Technical Leader, CFD/Tools, Hydraulic Engineering R\&D, Thi.Vu@andritz.com

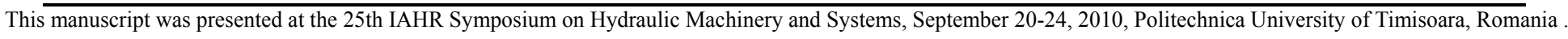



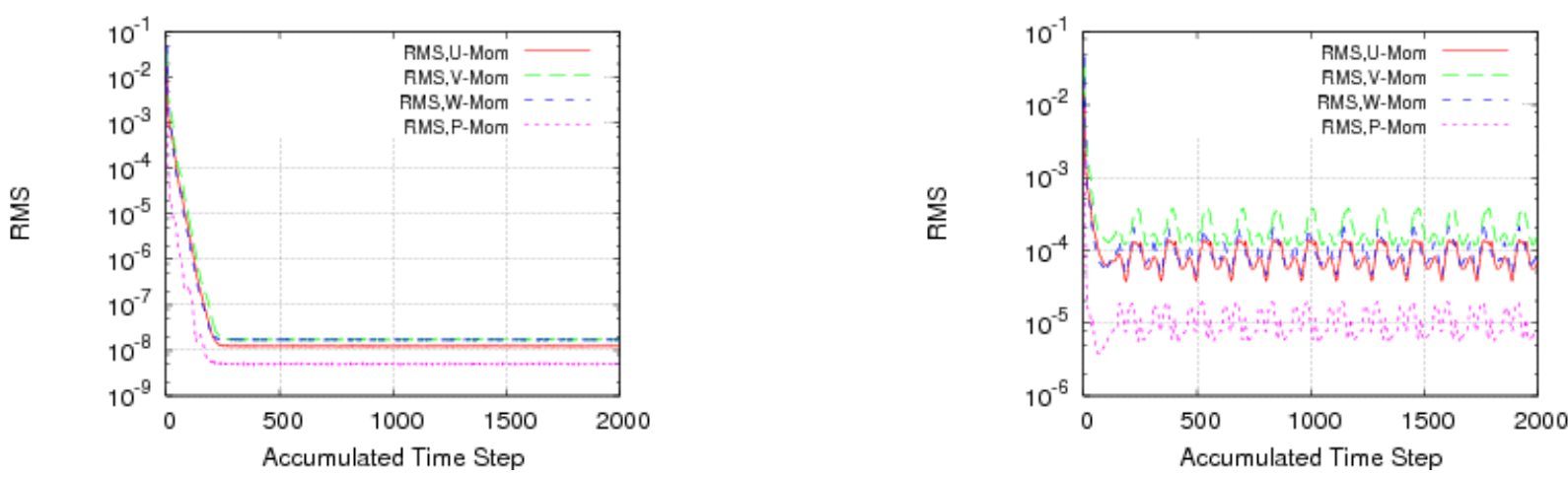

Fig. 1 CFX steady state convergence history for stable (left) and unstable solution (right)

As can be observed, for some operating conditions, residuals cannot decrease fully to a prescribed convergence criterion. Analysts generally associate such a convergence behavior to the probable evidence of unsteady flow phenomena in the solution, but a question then remains as to whether the steady state solution, when averaged over a number of periods, constitutes an adequate estimation of the unsteady solution. In order to verify the hypothesis that steady state computations do in fact reach the correct limit value, two computational approaches have been considered to compute the pressure recovery coefficient in cases where the convergence of the steady state flow simulations were oscillatory. Results are then compared with experimental results from the FLINDT project. These approaches are 1) to average the periodic pressure recovery factor values obtained using a steady state simulation over a number of periods and 2) to compute the time average of the fluctuating pressure response of an unsteady flow simulation.

During the process of CFD validation for the draft tube, several parameters have been considered for the study, such as mesh density [5], turbulence modeling, type of inlet boundary condition, turbulence condition at inlet, etc. The inlet flow condition for the draft tube can be simply specified as an axi-symmetrical flow profile or can be obtained directly from the runner by performing stage simulation with coupled runner-draft tube components. The turbulence conditions such as the turbulence kinetic energy and the turbulence kinetic dissipation must be also specified as part of the inlet flow conditions for the k- $\varepsilon$ turbulence model. Such information is not well known and the user has to make a well educated guess for the inlet turbulence flow condition. During the course of the study, we have found that this type of information could influence greatly the convergence behavior of the numerical solution and the finding is included in this paper. Also, in order to broaden the perspective on this issue, two distinct flow solvers are considered in this study, ANSYS-CFX12.1 and OpenFOAM-1.5dev.

\section{FLINDT test case}
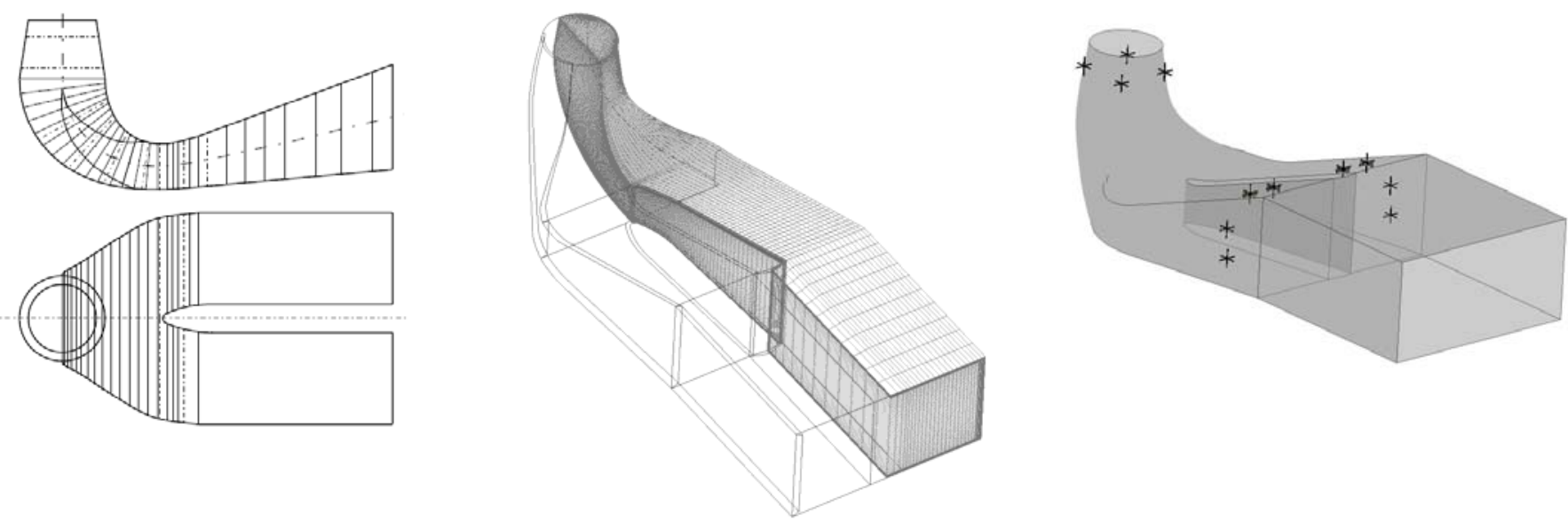

Fig. 2 FLINDT draft tube geometry

Fig. 3 Hexa mesh and monitoring points of FLINDT draft tube

As a test case, we have chosen the draft tube of the FLINDT project, investigated in a Francis turbine model of high specific speed, $\mathrm{n}_{\mathrm{q}}=88$. It is a symmetrical elbow draft tube with one pier (see Fig. 2). The geometry of the draft tube was carefully selected in order to obtain the desired efficiency drop toward the full load condition. Details on the FLINDT project are described in Refs. [1] and [6]. The draft tube flow behavior and pressure recovery factor have been investigated at several operating conditions of the runner. Wall static pressure measurements near the inlet section and at the draft tube outlet allow us to calculate the draft tube pressure recovery factor which is defined as the static pressure difference between inlet and outlet divided by the kinetic energy at the inlet. Six operating points having the same speed coefficient $\psi$ and various flow coefficients $\varphi$, covering full load to part load conditions, were selected for the study. LDV measurements of velocity profile and turbulent kinetic energy profile at the draft tube inlet are used as inlet boundary conditions for the CFD simulation. 
The geometry of the draft tube was imported into XMD, an Andritz design tool for draft tube geometry. A single multi-bloc structured mesh combining an O-type block structure near all solid walls and a H-type for the inside flow domain was generated using the in-house automatic draft tube mesh generator DTmesh [7]. The generated mesh with 675K nodes as shown in Fig. 3 was exported in the CGNS format [8], allowing the same mesh to be used with both flow solvers. Figure 3 shows also positions of monitoring points used during the computation, which match positions of pressure taps at the draft tube inlet (4 points) and outlet (8 points) during the experimental investigations.

As mentioned above, the axi-symmetrical velocity profiles and the turbulence kinetic energy profile are obtained from LDV measurements. Since no measurements were available to specify the value of the eddy dissipation, the inlet turbulence eddy dissipation profile was calculated using a mixing length scale $L_{T}$ model. According to CFX documentation [9], the eddy dissipation rate is related to the turbulent kinetic energy through the following relation: $\varepsilon=k^{3 / 2} / L_{T}$. The mixing length scale therefore constitutes a parameter that must be correctly calibrated in order for the simulations to match experiments. Three values have been used in this study: $1 \%, 0.5 \%$ and $0.25 \%$ of the runner throat diameter $\left(\mathrm{D}_{\text {th }}\right)$.

\section{Case study using ANSYS-CFX}

\subsection{Numerical model}

The first part of the study uses the ANSYS-CFX-12.1 commercial software. Standard RANS and URANS models using a twoequation $\mathrm{k}-\varepsilon$ turbulence closure model were used to perform all computations. CFX is a code based on the finite volume method which implements several discretization schemes. All computations were performed using the high-resolution scheme for the momentum equations, and the first order upwind scheme for the turbulent advection equations. A non-slip condition was imposed for all solid surfaces. At the outlet, an average static pressure over the whole outlet was specified. Six operating conditions with 3 different inlet turbulence length scales were computed and compared to the pressure recovery factor which is defined as:

$\chi=\Delta \mathrm{P}_{\text {stat }} /\left(1 / 2 \rho\left(\mathrm{Q} / \mathrm{A}_{\text {ref }}\right)^{2}\right) . \Delta \mathrm{P}_{\text {stat }}$ is the average pressure difference between inlet and outlet planes of measurement, $\rho$ the fluid density, and $\mathrm{Q}$ the mass flow rate through reference area $\mathrm{A}_{\text {ref. }}$.

For standard steady state computations, the convergence criterion is usually set to $1 \times 10^{-5}$ on the root mean square (RMS) residuals for all main variables. For monitoring purposes, the convergence criterion was instead set to a very strict value at $1 \times 10^{-12}$ RMS and a maximum of 2000 iterations was imposed for all computations. The CFX time step option for steady state cases was set to auto timescale and the timescale factor set to 1.0. Convergence history was also verified by the pressure monitoring points and this allowed computing the pressure recovery coefficient at each iteration.

\subsection{Results with steady flow simulations}

Figure 4 illustrates the convergence behavior and comparison with experiment of the pressure recovery factor value for steady state computations obtained using CFX-12.1. The numerical pressure recovery factor is obtained by averaging the periodic pressure recovery factor values obtained using steady state simulation over a number of periods. The mean value has a high and low bound corresponding to the monitored fluctuation values illustrated as error bars in Fig. 4.

As can be observed in Fig. 4, turbulence boundary conditions at the inlet have a significant influence on the simulation results. A lower value of the dissipation length scale leads to a smaller turbulent to molecular viscosity ratio, leading to less energy dissipation and a generally more unsteady behavior for some operating conditions.

In the present case, a value of $L_{T}=0.5 \% D_{t h}$ appears to strike an adequate balance between stability and sensitivity to flow features. For this set of computations, there is a very large fluctuation of the pressure recovery factor for the operating point $\varphi=0.38$ and a moderate fluctuation for $\varphi=0.39$. When inlet turbulent viscosity is increased, it is expected that the amplitude of fluctuations of the pressure recovery factor be reduced, but this is not the case as observed with the results obtained for $L_{T}=1 \% D_{t h}$. For this inlet condition, the amplitude of fluctuations of the pressure recovery factor at $\varphi=0.38$ remains the same and we get another point $(\varphi=0.36)$ having a non-convergent periodic behavior. For $L_{T}=0.25 \% D_{t h}$, three operating conditions show a nonconvergent periodic behavior: $0.368,0.38$ and 0.39 and the pressure recovery factor of the BEP $(\varphi=0.368)$ is not well predicted.

Figures 5 shows the evolution of the turbulence viscosity in the draft tube cone at $\varphi=0.368$ for 3 values of $L_{T}=1.0 \% D_{t h}$, $0.5 \% D_{t h}$ and $0.25 \% D_{t h}$ as boundary condition at the draft tube inlet. The illustration shows the variation of the relative turbulent viscosity from 0 to 1000 . The relative turbulence viscosity is defined as $\mu_{\mathrm{t}} / \mu$, where $\mu_{\mathrm{t}}$ and $\mu$ are the turbulent viscosity and the dynamic viscosity respectively. The turbulence viscosity in the draft tube cone is dictated mainly by the prescribed turbulence viscosity at the draft tube inlet but increases rapidly at the draft tube cone center and further in the downstream region. The red areas indicate locations where turbulence viscosity ratio is higher than 1000 . The general pattern remains the same for the 3 turbulent inlet conditions.

In Figure 6 we can observe the evolution of the turbulence viscosity at the two extreme operating conditions, $\varphi=0.34$ (part load), $\varphi=0.41$ (full load) and also for $\varphi=0.38$, for the same value of $L_{T}=0.5 \% D_{t h}$. For operating condition $\varphi=0.34$ at part load where highly swirling flow is taking place at the draft tube cone, the turbulent viscosity develops rapidly and the region with turbulent viscosity ration higher than 1000 occupies a large portion of the draft tube cone and the elbow. This is the reason why the numerical solution is very stable at this operating condition as shown in Fig. 4. This high turbulent viscosity region decreases as the swirl intensity decreases in the draft tube cone as observed for $\varphi=0.368$ (Fig. 5) and $\varphi=0.38$. For the operating condition $\varphi=0.41$ at full load, the high turbulence viscosity is not present in the draft tube cone but increases rapidly in the elbow region where a flow recirculation is taking place at the draft tube elbow ceiling. 


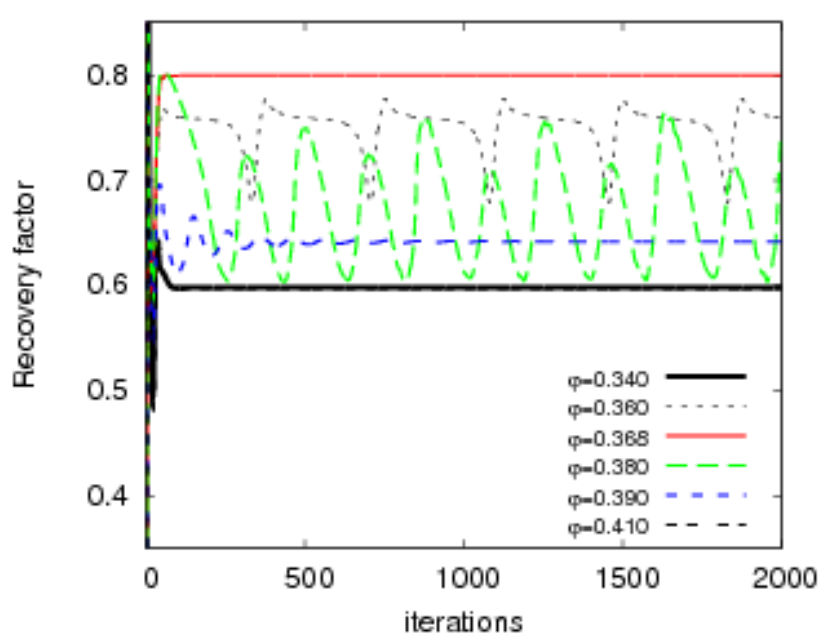

a) Recovery factor vs. iteration number $\left(\mathrm{Lt}=1 \% \mathrm{D}_{\text {th }}\right)$

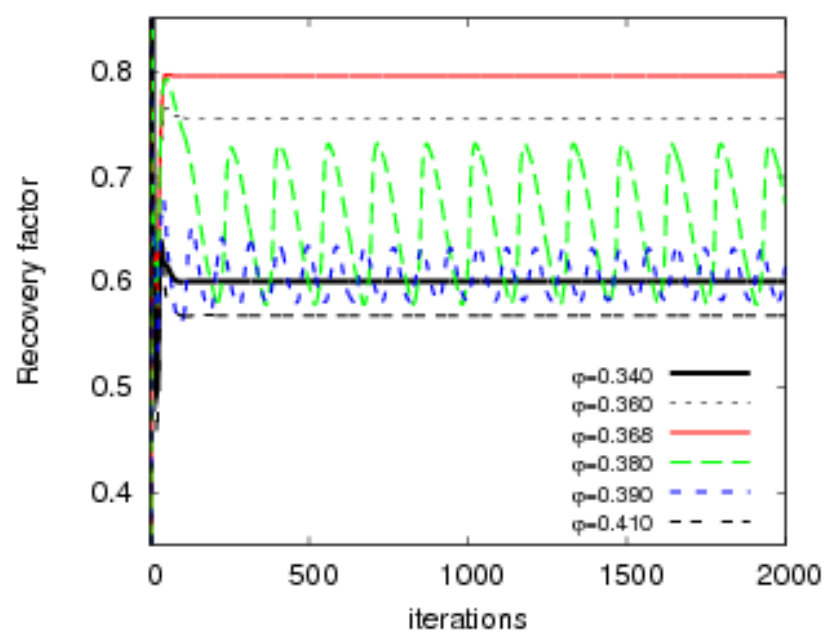

c) Recovery factor vs. iteration number $\left(\mathrm{Lt}=0.5 \% \mathrm{D}_{\mathrm{th}}\right)$

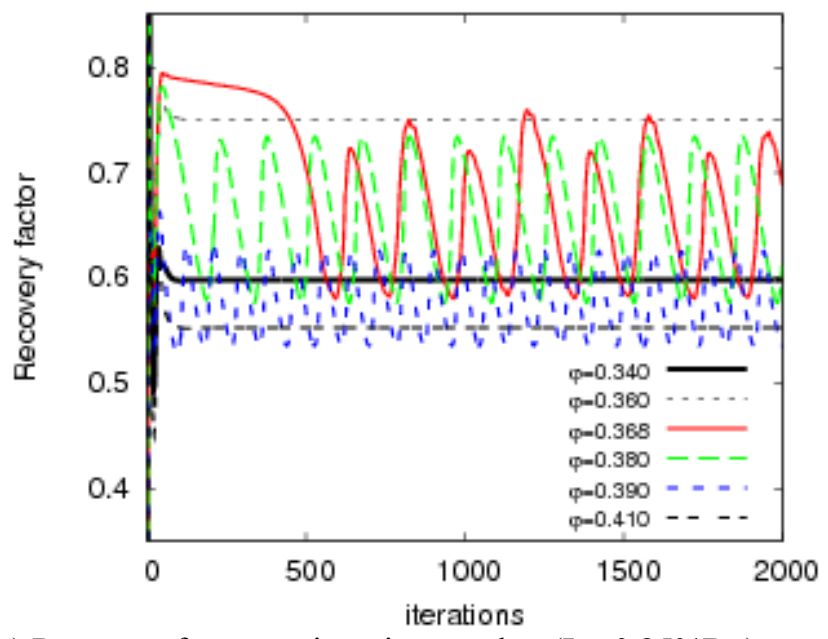

e) Recovery factor vs. iteration number $\left(\mathrm{Lt}=0.25 \% \mathrm{D}_{\mathrm{th}}\right)$

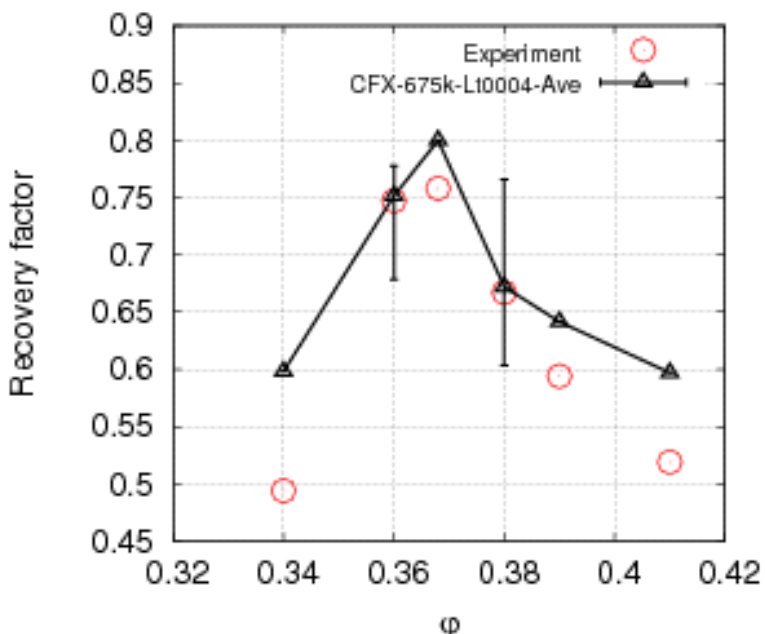

b) Recovery factor vs. flow coefficient $\left(\mathrm{Lt}=1 \% \mathrm{D}_{\mathrm{th}}\right)$

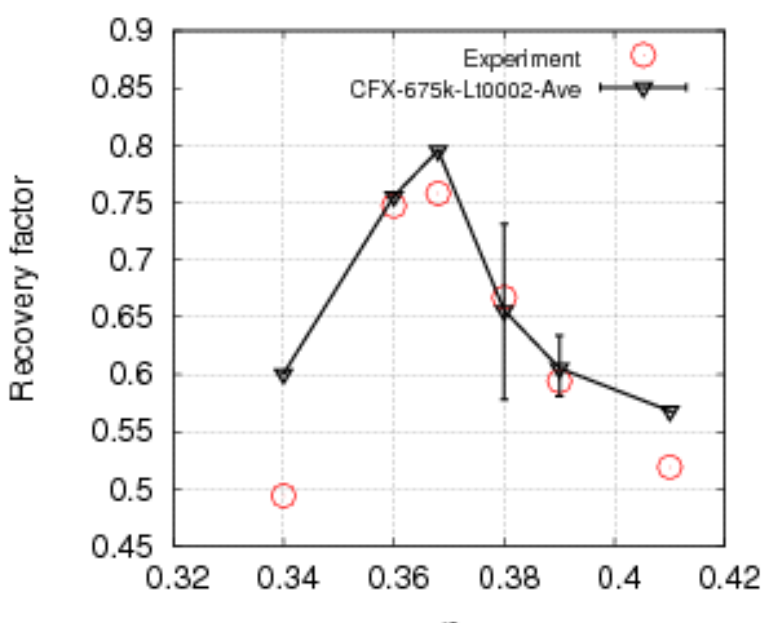

d) Recovery factor vs. flow coefficient $\left(\mathrm{Lt}=0.5 \% \mathrm{D}_{\mathrm{th}}\right)$

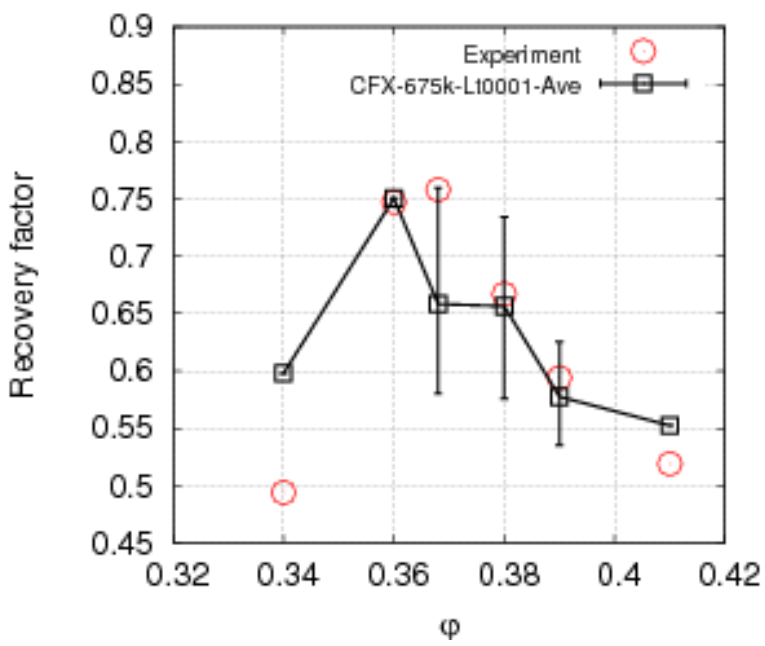

f) Recovery factor vs. flow coefficient $\left(\mathrm{Lt}=0.25 \% \mathrm{D}_{\text {th }}\right)$

Fig. 4 Pressure recovery factor prediction for three levels of turbulent energy dissipation for CFX 

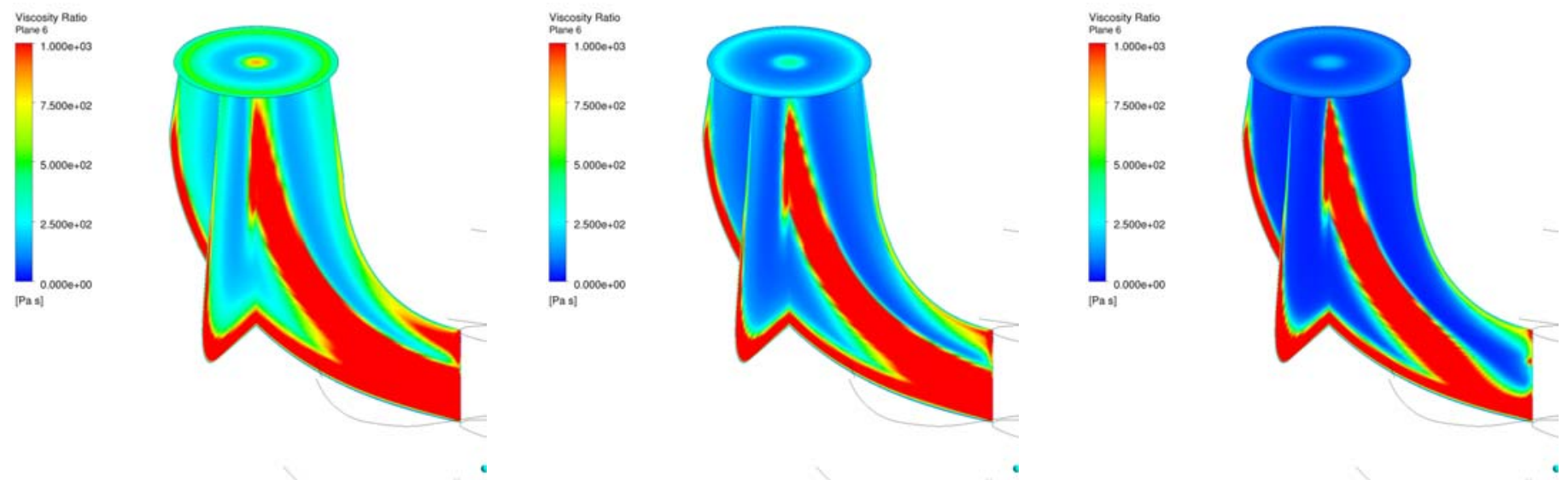

Fig. 5 Viscosity ratio at BEP $\varphi=0.368-\mathrm{Lt}=1 \% \mathrm{D}_{\text {th }}, \mathrm{Lt}=0.5 \% \mathrm{D}_{\text {th }}$ and $\mathrm{Lt}=0.25 \% \mathrm{D}_{\text {th }}(\mathrm{CFX})$
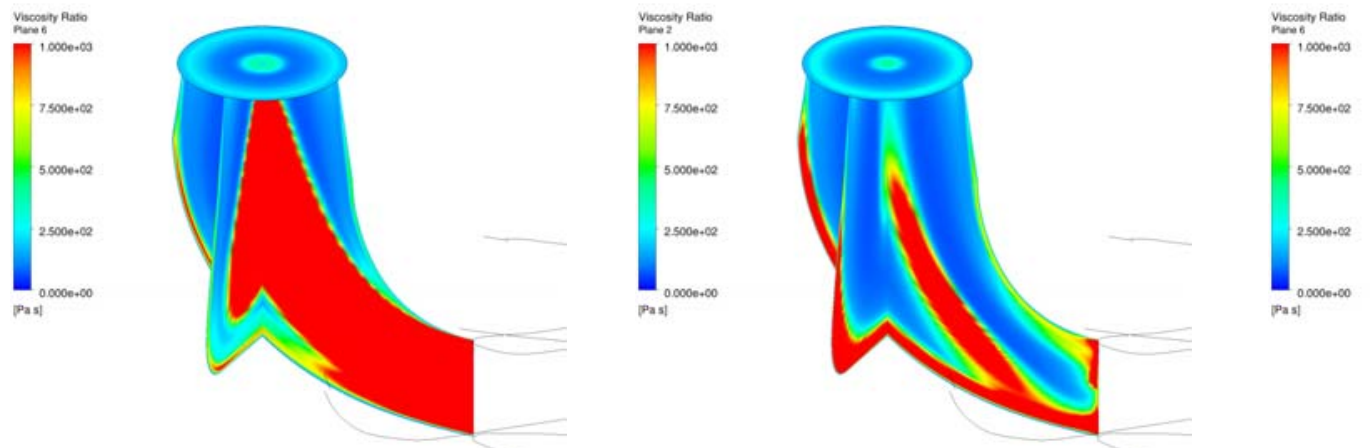

$t^{2}-\mathrm{x}$

4

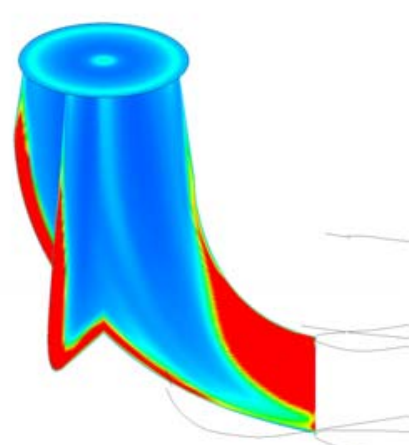

4

Fig. 6 Viscosity ratio at operating point $\varphi=0.34, \varphi=0.38$ and $\varphi=0.41-\mathrm{Lt}=0.5 \% \mathrm{D}_{\text {th }}$ (CFX)

Figure 7 shows the position of the experimental measurement plans in the FLINDT draft tube. Section 1.75 stands at the end of the draft tube cone and Section 15.5 is upstream of the pier nose. Comparison of numerical result with experimental data at the two measurement plans has been carried out for all operating conditions. As example, comparison plots for pressure, velocity (normal, radial and tangential components) and energy E are shown in Fig. 8 for two operating conditions $\varphi=0.368$ (BEP) and $\varphi$ $=0.38$. In general, the numerical results match well with the experimental data for all cases.

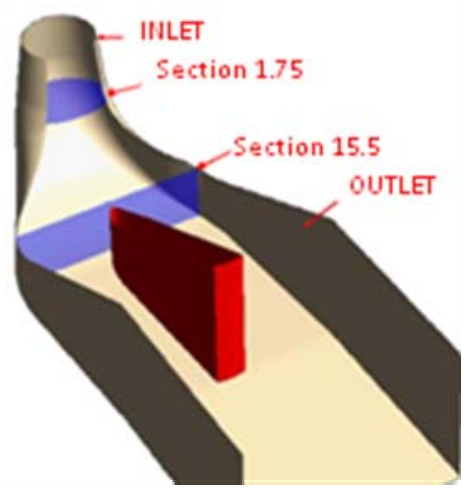

Fig. 7 Position of the experimental planes. 


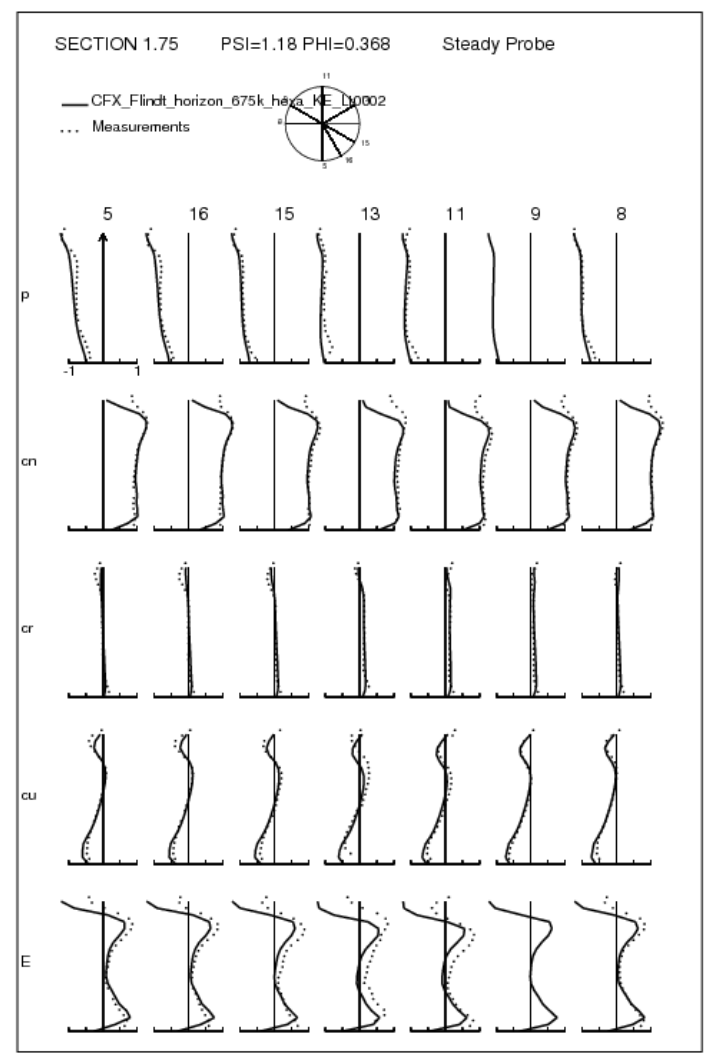

Profile for $\mathrm{Lt}=0.5 \% \mathrm{D}_{\text {th }}$ at operating point $\varphi 0.368$ for section 1.75

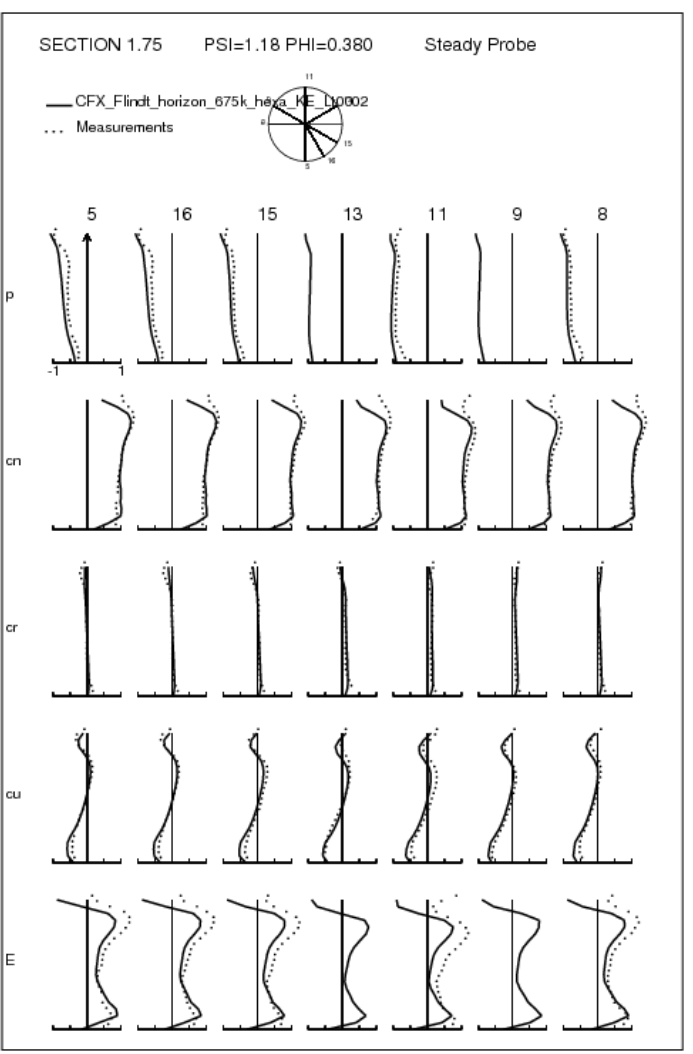

Profile for $\mathrm{Lt}=0.5 \% \mathrm{D}_{\text {th }}$ at operating point $\varphi=0.380$ for section 1.75

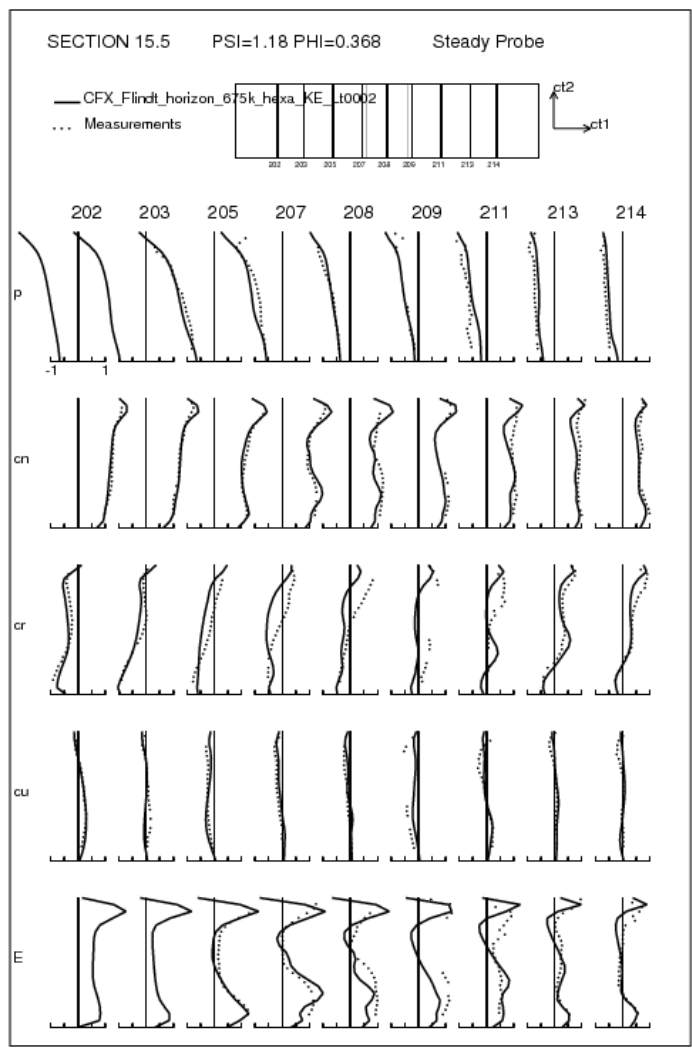

Profile for $\mathrm{Lt}=0.5 \% \mathrm{D}_{\text {th }}$ at operating point $\varphi=0.368$ for section 15.5

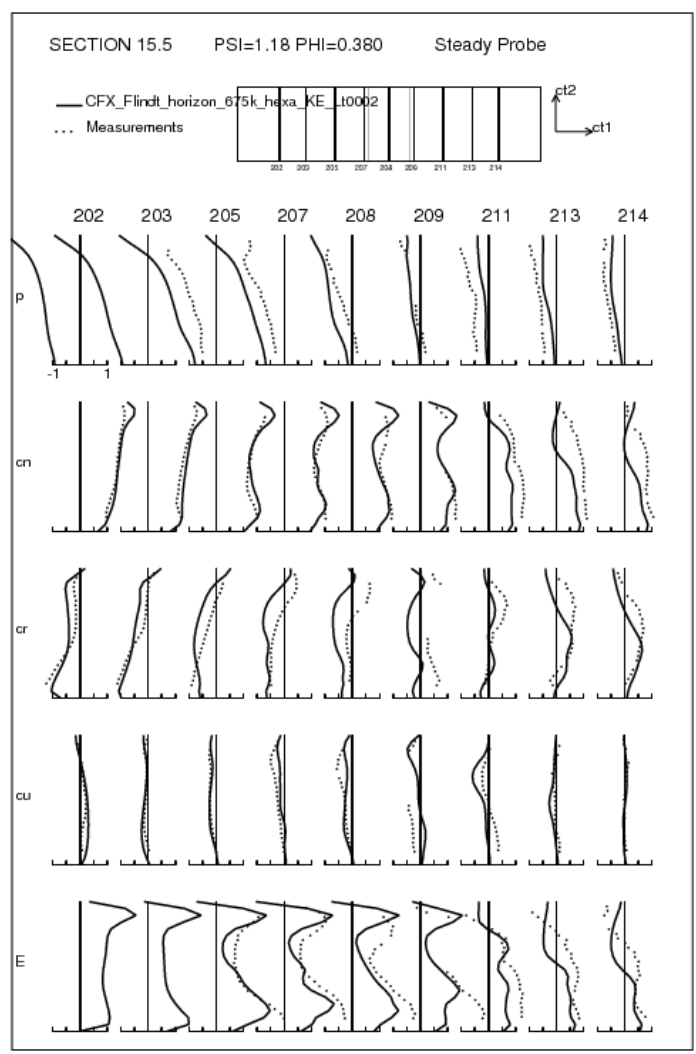

Profile for $\mathrm{Lt}=0.5 \% \mathrm{D}_{\text {th }}$ at operating point $\varphi=0.380$ for section 15.5

Fig. 8 Comparison between numerical (CFX) and experimental data.

\subsection{Results with unsteady flow simulations}

A second set of computations was performed for a subset of the operating conditions, $L t=0.5 \% D_{t h}$, this time using an unsteady problem formulation. Each unsteady computation was initialized using the previously computed steady solution for the same 
operating point. We have chosen the operating point $\varphi=0.38$, which exhibited the largest fluctuation amplitude for the steady flow computation, as an example. Also this is the operating point where the turbine efficiency has a sudden dramatic drop. The time steps were set to correspond respectively to increments of $6^{\circ}, 1^{\circ}$ and $0.5^{\circ}$ of the runner rotation. Figure 9 a) illustrates the behavior of the pressure recovery factor as a function of iteration number, and the transition between steady and unsteady computations that occurred at iteration 2000 (time 117.2s), 5255 (time 1021.4s) and 6300 (time 1069.8s). As can be observed, the amplitude of the recovery factor fluctuation is affected by the change in time step. However, the average value of the recovery factor computed over several periods of the steady computations is extremely close to the temporal average computed in unsteady mode. This observation is confirmed numerically in Table 1 for which both averages correspond quite precisely with the experimental value.

Table 1 Comparison of steady and unsteady averages of the recovery factor for $\varphi=0.38$ and $\mathrm{L}_{\mathrm{T}}=0.5 \% \mathrm{D}_{\text {th }}$

\begin{tabular}{|l|c|c|c|c|c|}
\hline & Steady state & $\begin{array}{c}\text { Transient state } \\
\Delta \mathrm{t}=0.27 \mathrm{~s}\left(6^{\circ}\right)\end{array}$ & $\begin{array}{c}\text { Transient state } \\
\Delta \mathrm{t}=0.046 \mathrm{~s}\left(1^{\circ}\right)\end{array}$ & $\begin{array}{c}\text { Transient state } \\
\Delta \mathrm{t}=0.023 \mathrm{~s}\left(0.5^{\circ}\right)\end{array}$ & Experiment \\
\hline Min & 0.5780 & 0.5739 & 0.5389 & 0.5340 & \\
\hline Average & 0.6557 & 0.6547 & 0.6803 & 0.6634 & 0.667 \\
\hline Max & 0.7313 & 0.7382 & 0.7556 & 0.7309 & \\
\hline
\end{tabular}

Figures 9b), 9c) and 9d) show the recovery factor as a function of time at the different transition from steady state to $6^{\circ}$ time step, from $6^{\circ}$ time step to $1^{\circ}$ time step, and from $1^{\circ}$ time step to $0.5^{\circ}$ time step respectively. As observed in Fig $9 \mathrm{a}$ ), the amplitude of the recovery factor changes but the period remains constant.
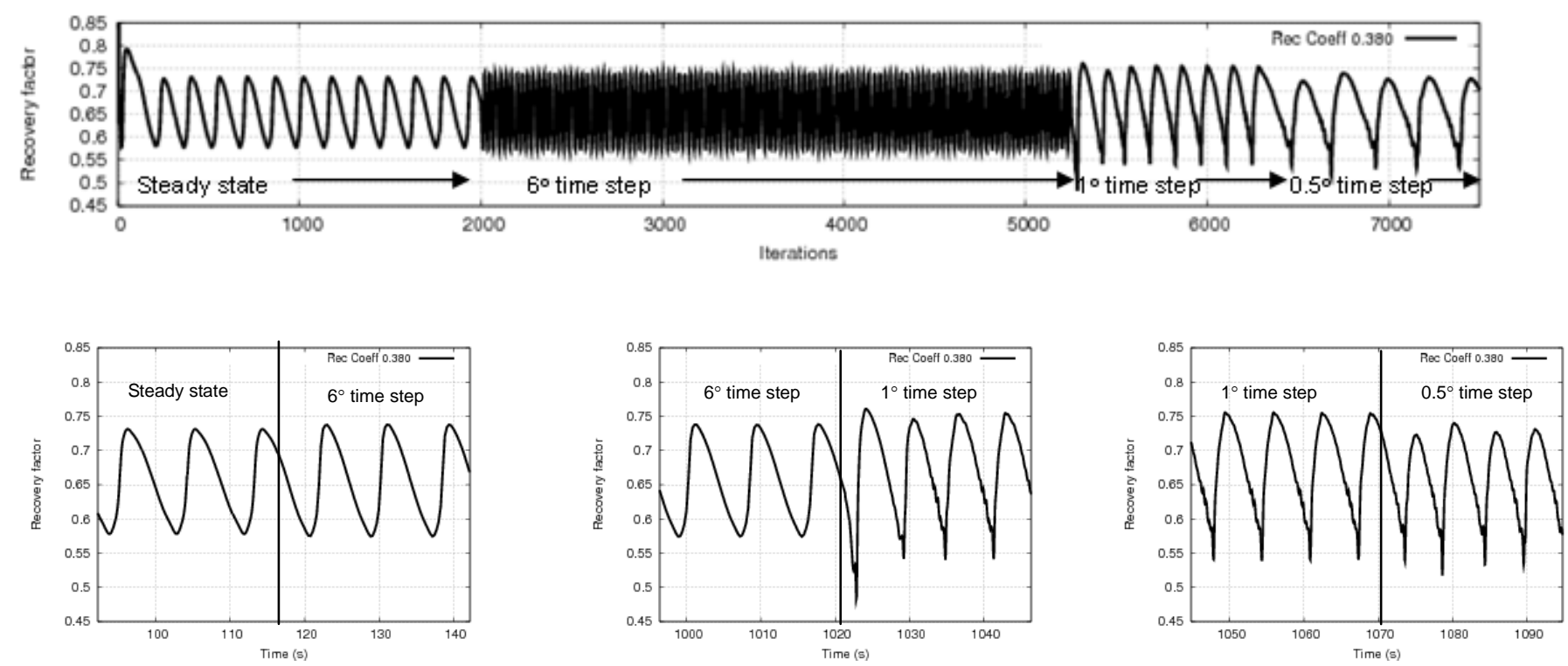

Fig. 9 Fluctuation of the pressure recovery factor versus (a) iteration number and versus (b-c-d) time $-\varphi=0.38-L t=0.5 \% D_{\text {th }}$

For this particular point of operation, the unsteadiness of the numerical solution is due to an intermittent flow detachment from the pier wall in the left draft tube channel, as shown in Fig. 10, which represents snapshots of the evolution of the velocity at different time steps during one period. The figures on the left hand side show the velocity contours at different vertical plans in the draft tube, while the figures on the right show the velocity contours at a horizontal plan near the draft tube ceiling. Due to the intermittent flow detachment behavior, the flow rate distribution between the two draft tube channels keeps changing and this explains a large drop on the turbine efficiency at this operating point. 


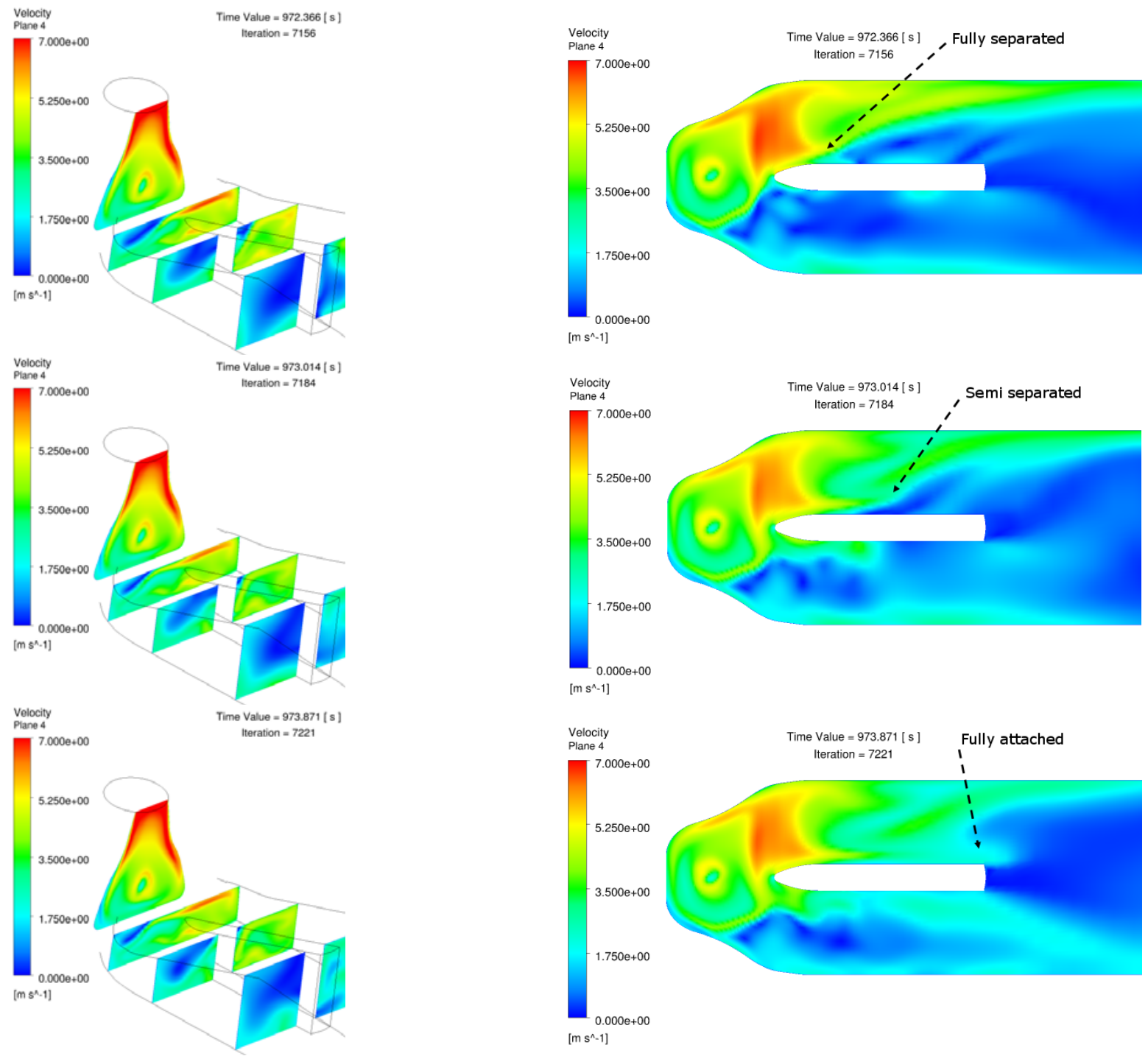

Fig. 10 Unsteady flow behavior at operating point $\varphi=0.38-\mathrm{Lt}=0.5 \% \mathrm{D}_{\text {th }}(\mathrm{CFX})$

On the contrary, Fig. 11 represents a stable flow behavior at the $\operatorname{BEP} \varphi=0.368$.
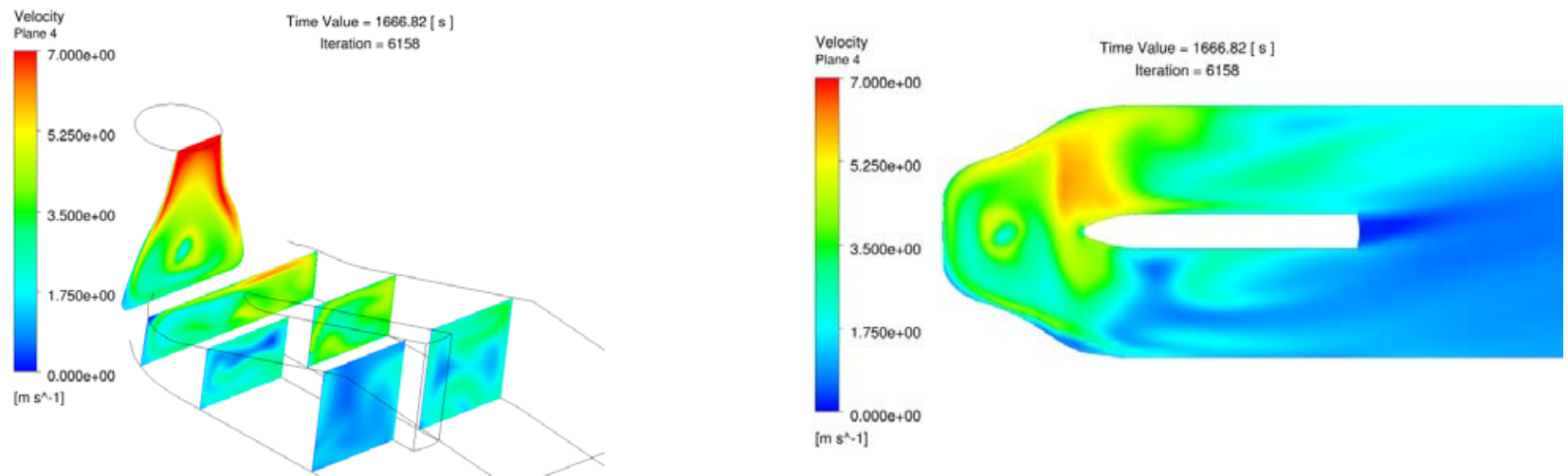

Fig. 11 Flow behavior at operating point $\varphi=0.368(\mathrm{BEP})-\mathrm{Lt}=0.5 \% \mathrm{D}_{\text {th }}(\mathrm{CFX})$

\section{Case study using OpenFOAM}

In order to verify the generality of the proposed approach, OpenFOAM-1.5dev was used to perform steady state flow analysis for the same setting of the inlet condition as described in paragraph 3. 


\subsection{Numerical model}

The SimpleFoam flow solver was used for the steady state flow computations. In terms of numerical scheme, an upwind convection scheme was used for all terms except div $(\Phi, \mathrm{U})$, for which an improved bounded normalized variable diagram $(\mathrm{NVD})$ scheme GammaV was specified with a coefficient $\psi=1.0$. To solve the flow equations, the pre-conditioned (bi-) conjugate gradient (PBiCG) linear solver was used for all variables except pressure, for which the generalized geometric-algebraic multi-grid (GAMG) was specified.

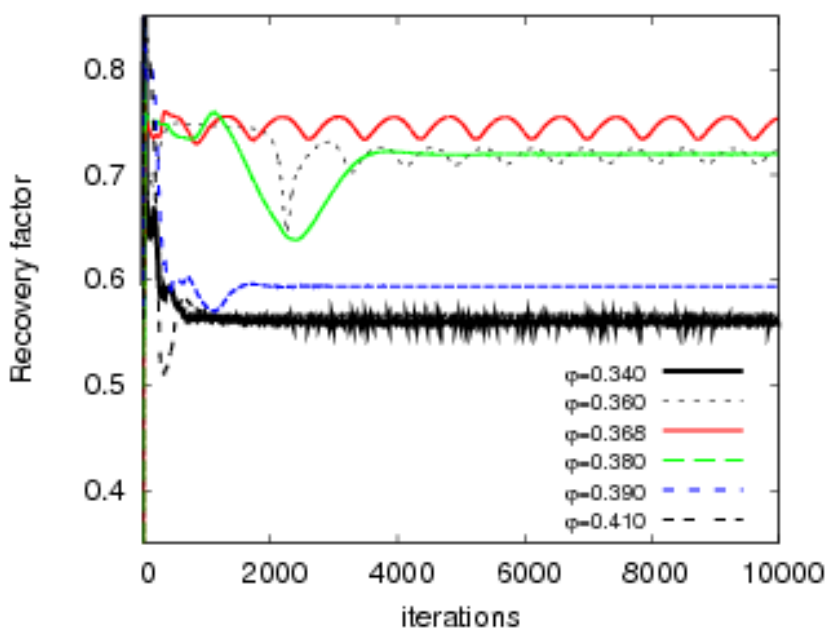

a) Recovery factor vs. iteration number $\left(\mathrm{Lt}=1 \% \mathrm{D}_{\mathrm{th}}\right)$

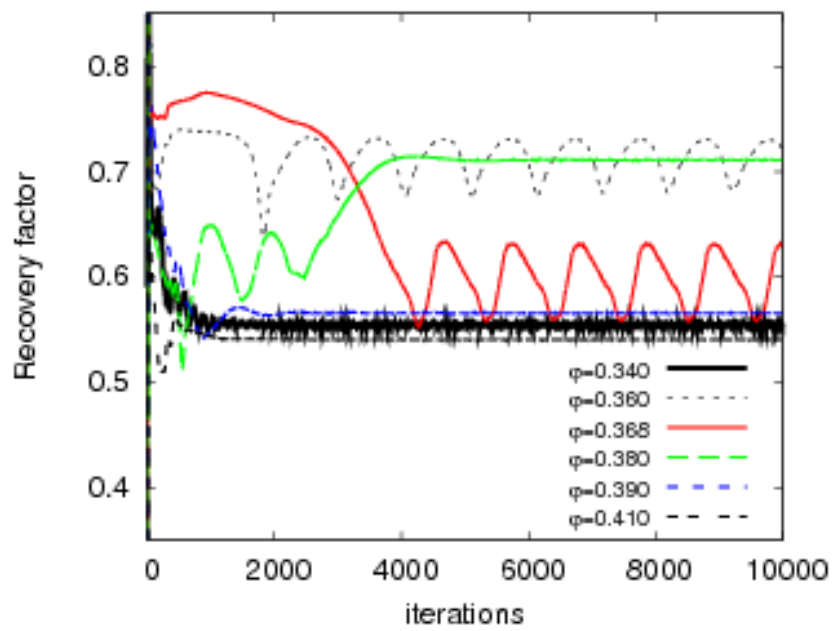

c) Recovery factor vs. iteration number $\left(\mathrm{Lt}=0.5 \% \mathrm{D}_{\text {th }}\right)$

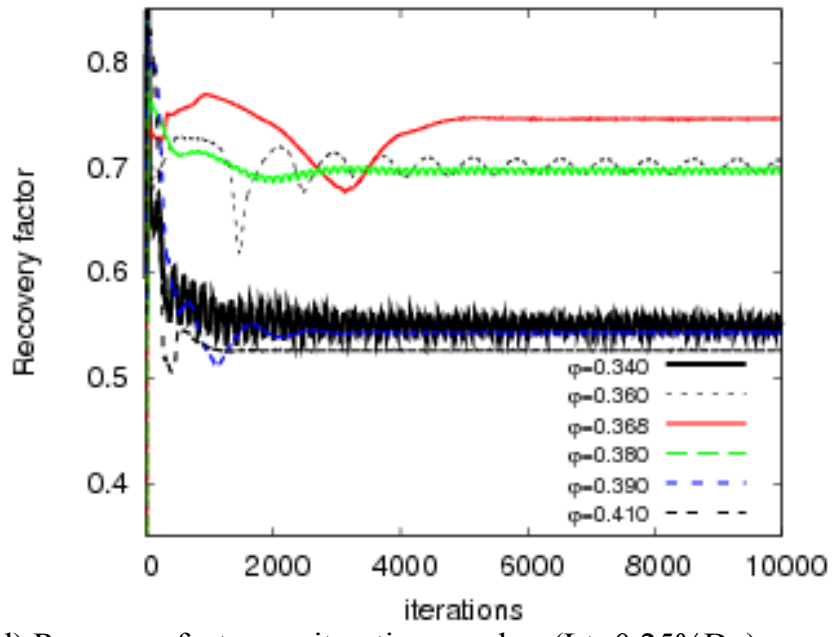

d) Recovery factor vs. iteration number $\left(\mathrm{Lt}=0.25 \% \mathrm{D}_{\mathrm{th}}\right)$

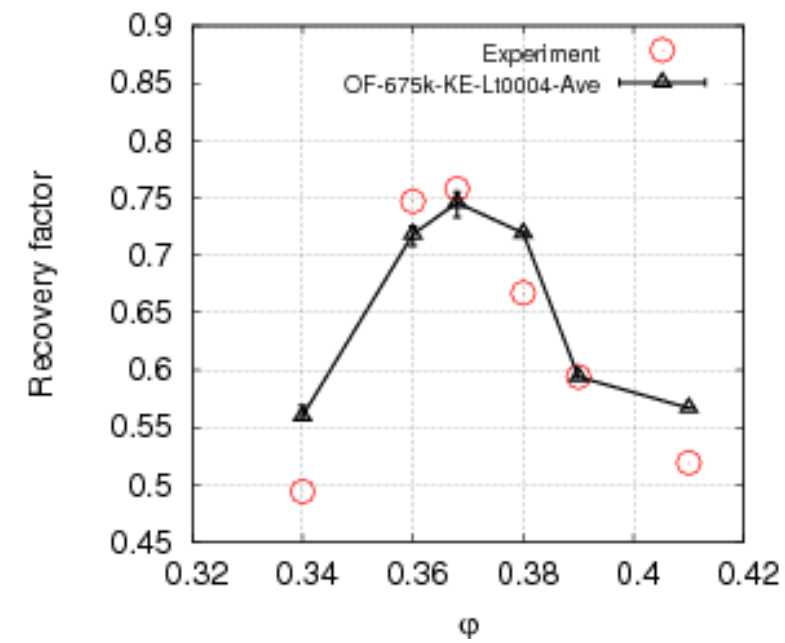

b) Recovery factor vs. flow coefficient $\left(\mathrm{Lt}=1 \% \mathrm{D}_{\text {th }}\right)$

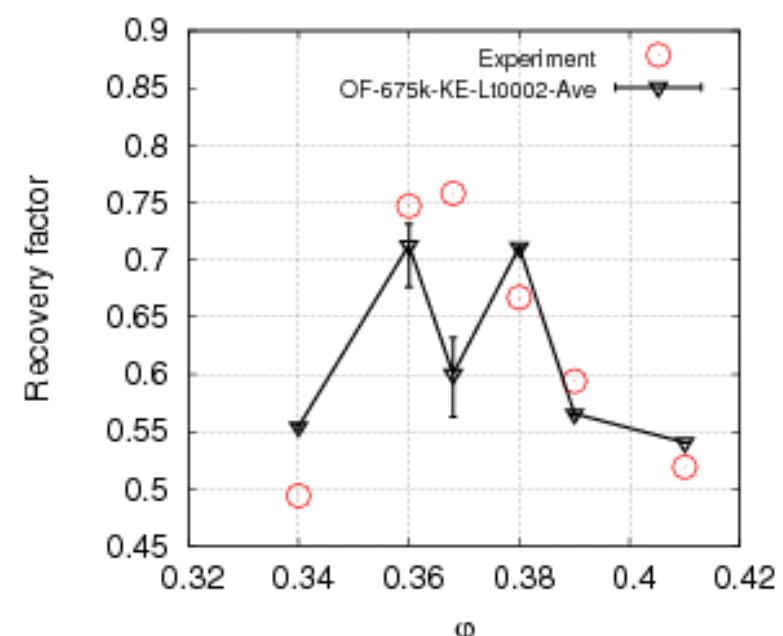

d) Recovery factor vs. flow coefficient $\left(\mathrm{Lt}=0.5 \% \mathrm{D}_{\mathrm{th}}\right)$

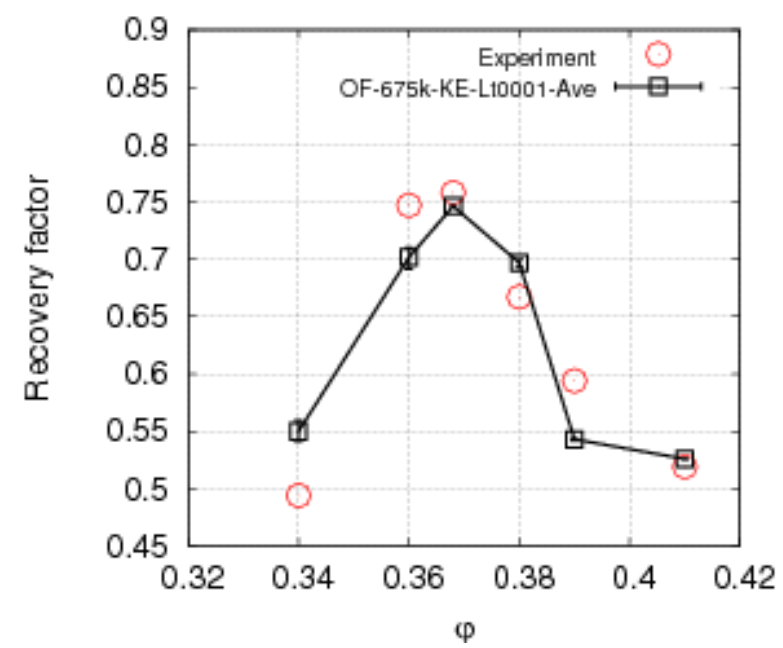

f) Recovery factor vs. flow coefficient $\left(\mathrm{Lt}=0.25 \% \mathrm{D}_{\text {th }}\right)$

Fig. 12 Pressure recovery factor prediction for three levels of turbulent energy dissipation for OpenFOAM. 
Absolute and relative solution tolerances (tolerance and relTol) were specified for each solution variable to control the equation solvers convergence. tolerance is applied to the residual evaluated by substituting the current solution into the equation and taking the magnitude of the difference between the left and right hand sides. relTol is the ratio of final over initial residual. In this study, a tolerance value of $1 . \mathrm{e}-5$ and a relTol value of 0.1 have been used for all variables except pressure, for which a tolerance value of 1.e- 6 and relTol 0.01 were applied. A relaxation factor of 0.3 for pressure and 0.7 for other variables was also applied to improve stability. A maximum of 10000 iterations have been performed. As inlet boundary conditions, the same velocity and turbulence profiles as in the previous case study were used.

\subsection{Results with steady flow simulations}

Figure 12 illustrates the convergence behavior and comparison with experiment of the pressure recovery factor value for steady state computations obtained using OpenFOAM. As OpenFOAM uses an uncoupled solver, it required more time steps to achieve a converged solution. One can observe that the turbulence boundary conditions at the inlet have a certain influence on the simulation results but to a lesser degree than with the ANSYS-CFX solver. Also, the unsteadiness of the solution is much less significant, which leads to a speculation that the algorithm used for the present computation is more diffusive. But overall, the solver could yield useful global quantities such as the pressure recovery factor of the draft tube. We would like to point out an abnormal convergence behavior of the solver, at the BEP $\varphi=0.368$ for $L_{T}=0.5 \% D_{t h}$. The solution stays stable for several thousand iterations and starts to oscillate around a bad pressure recovery factor. More investigation is needed for this operating point.

Figure 13 shows the relative turbulence viscosity distribution in the draft tube cone obtained with OpenFOAM for $\varphi=0.368$ for 3 values of $\mathrm{L}_{\mathrm{T}}, 1.0 \% \mathrm{D}_{\text {th }}, 0.5 \% \mathrm{D}_{\text {th }}$ and $0.25 \% \mathrm{D}_{\text {th }}$. Similar phenomena are observed as in Fig. 5 of section 4.2 for CFX results.
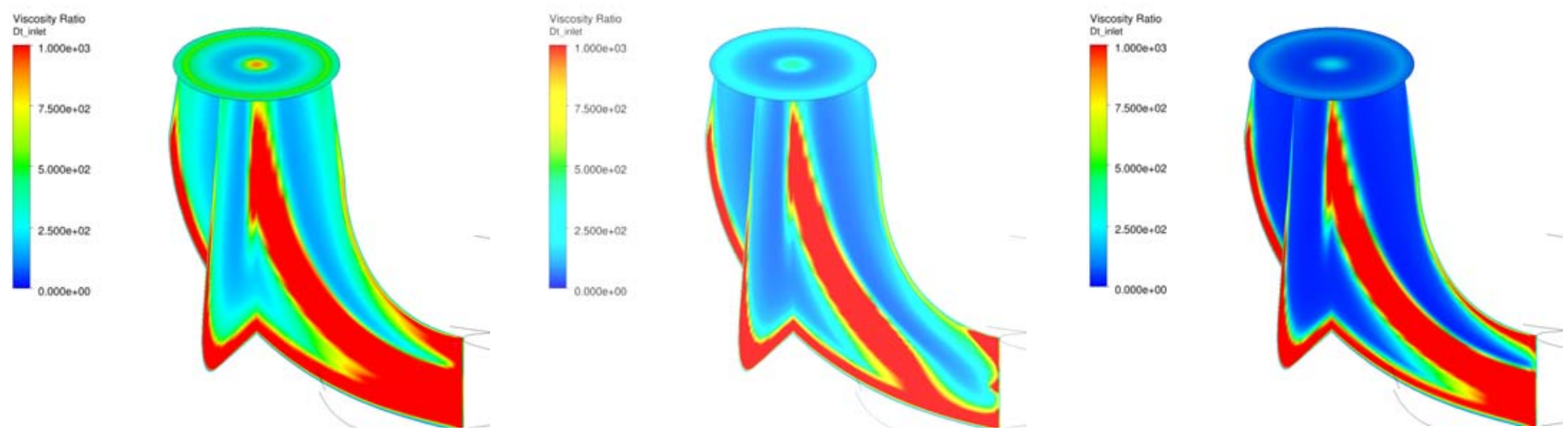

Fig. 13 Viscosity ratio at operating point $\varphi=0.368-\mathrm{Lt}=1 \% \mathrm{D}_{\text {th }}, \mathrm{Lt}=0.5 \% \mathrm{D}_{\text {th }}$ and $\mathrm{Lt}=0.25 \% \mathrm{D}_{\text {th }}($ OpenFOAM)

The comparison between the OpenFOAM results and experimental data at sections 1.75 and 15.5 has also been carried out for all operating conditions. As an example, we show in Fig. 14 the results for two operating conditions $\varphi=0.368$ and $\varphi=0.38$. As can be observed, profiles of all variables at these operating conditions are in general well predicted by the numerical simulation.

\section{Conclusion}

This paper has presented a validated numerical simulation approach to evaluate global draft tube performance. This approach, based on steady-state flow simulations using the k- $\varepsilon$ turbulence model and a moderately refined mesh, offers a highly effective methodology that can reliably be used by designers to compare relative global draft tube performance of nearby design operating points. This study demonstrates the importance of the choice of turbulent inlet boundary conditions even close to the best efficiency operating condition. The influence of these fluctuations, which are not related to the presence of a large vortex rope at the draft tube inlet, can correctly be averaged by steady-state simulations.

The ANSYS-CFX flow solver using the high-resolution scheme is very sensitive to inlet turbulence profile effects. Indeed, since the numerical scheme shows little diffusion, unsteady fluctuations are well detected. It is therefore very important to average global performance indicators such as the pressure recovery factor over an adequate number of periods to obtain correct results. In particular, for the FLINDT draft tube, unsteady phenomena were observed for the flow condition $\varphi=0.38$, for all eddy dissipation length scales considered. Detailed unsteady flow analyses have shown however that the averaged steady flow result computed using $L_{T}=0.5 \% D_{t h}$ was very close to time averages of unsteady simulations.

In the case of the OpenFOAM flow solver, the results obtained for the pressure recovery factor appear to be less sensitive to turbulence inlet boundary conditions. This behavior may be attributed to our choice of numerical scheme. This may explain also why we did not find large oscillating convergence behavior on the pressure recovery factor for all computation cases, especially for the operating point $\varphi=0.38$.

Another observation that can be made following the present validation case study is the fact that as the operating conditions move away from the best efficiency point, the predictive performance of the $\mathrm{k}-\varepsilon$ turbulence model tends to deteriorate. This is particularly the case for part load operating conditions $(\varphi=0.34)$, for which estimated performance are systematically overestimated. This can probably be attributed to unsteady phenomena inside the cone section of the draft tube, that are damped by the turbulence model used, even in unsteady simulation mode. Further investigation with more advanced turbulence models is required. 


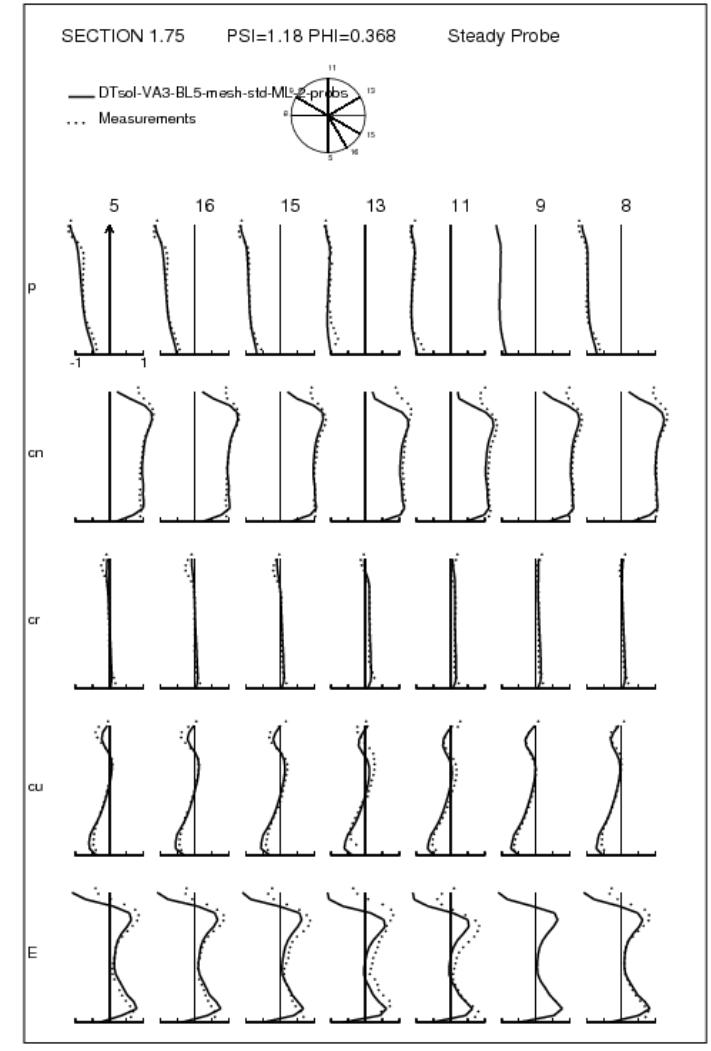

Profile for $\mathrm{Lt}=0.5 \% \mathrm{D}_{\text {th }}$ at operating point $\varphi=0.368$ for section 1.75

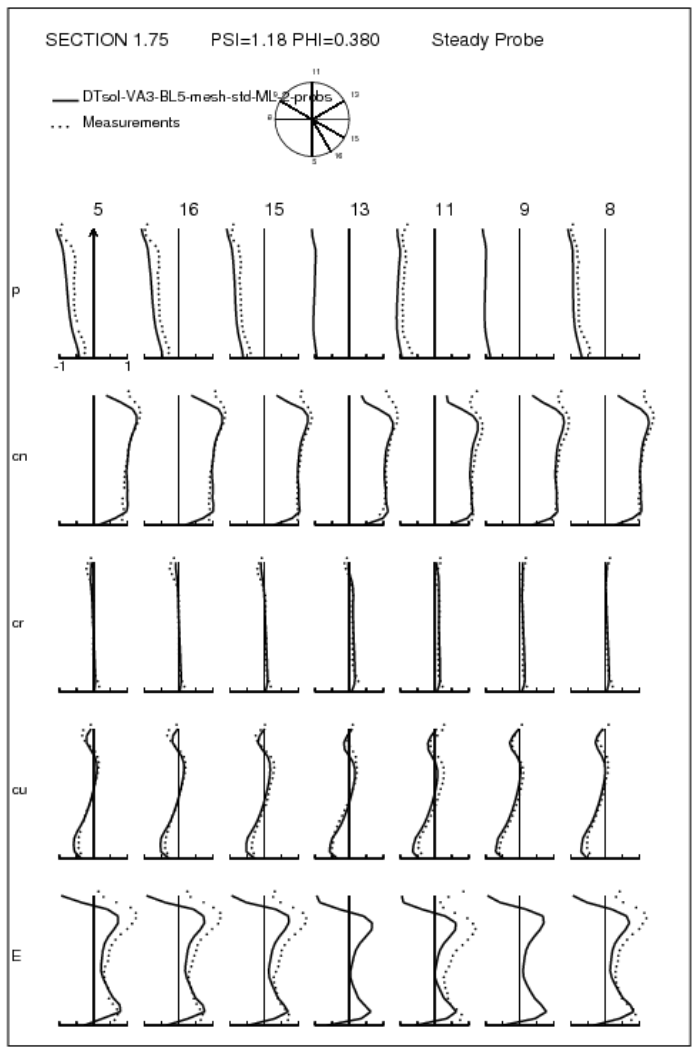

Profile for $\mathrm{Lt}=0.5 \% \mathrm{D}_{\text {th }}$ at operating point $\varphi=0.380$ for section 1.75

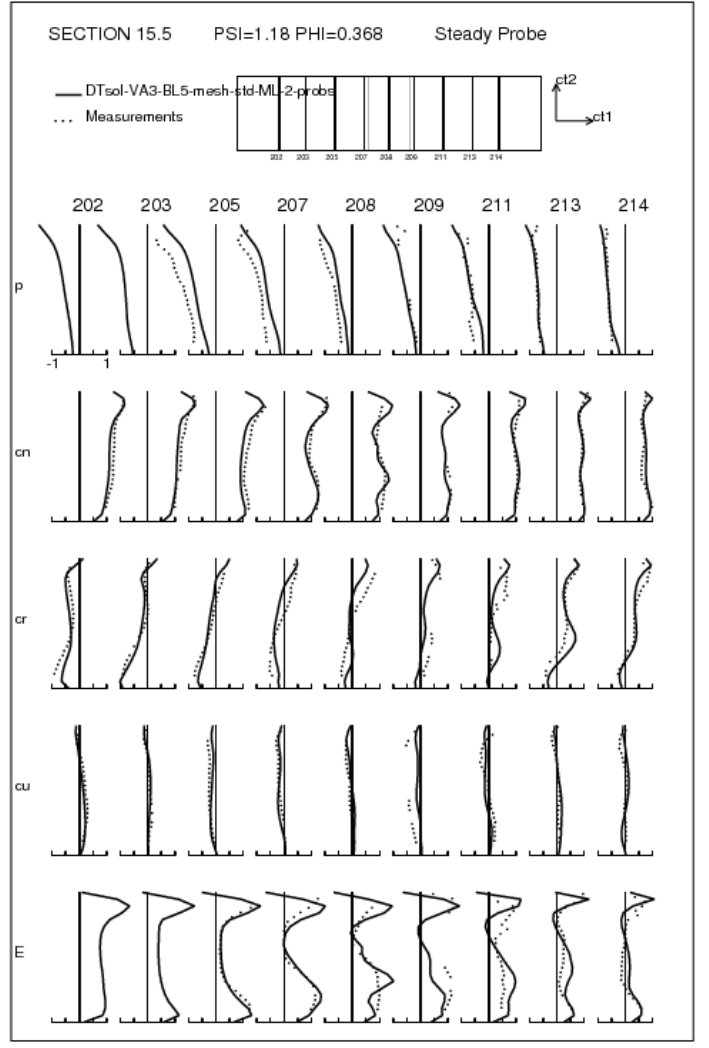

Profile for $\mathrm{Lt}=0.5 \% \mathrm{D}_{\mathrm{th}}$ at operating point $\varphi=0.368$ for section 15.5

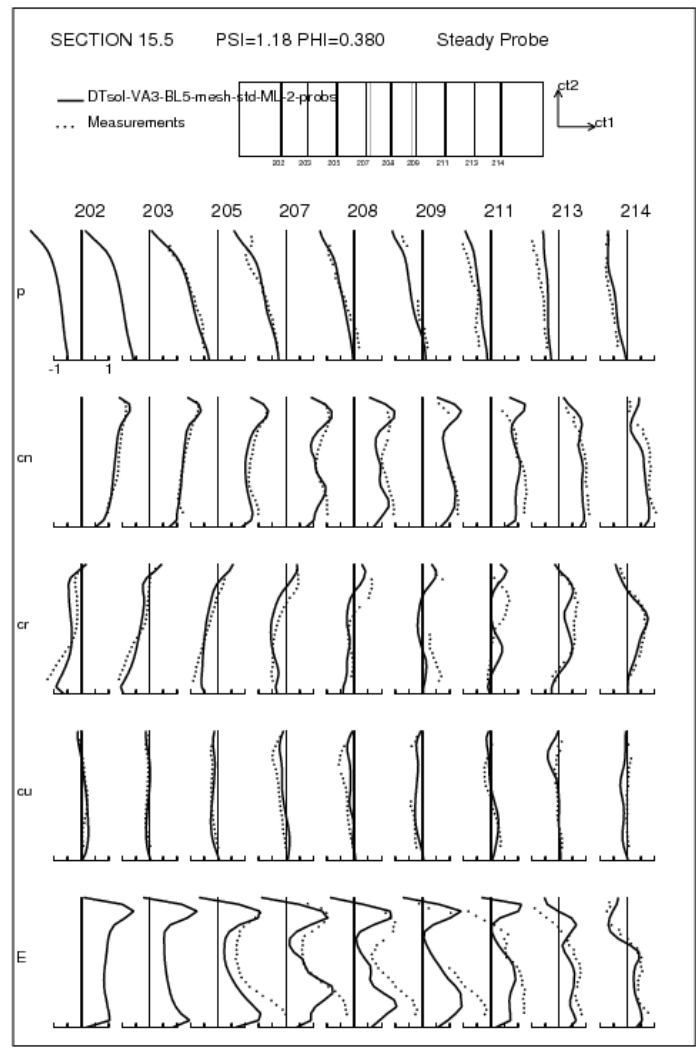

Profile for $\mathrm{Lt}=0.5 \% \mathrm{D}_{\mathrm{th}}$ at operating point $\varphi=0.380$ for section 15.5

Fig. 14 Comparison between numerical (OpenFOAM) and experimental data. 
For both flow solvers, good estimations of global quantities and excellent correlation of computed velocity profiles with experimental measures were obtained, as demonstrated by the velocity profile results.

Finally, a comment must be made regarding the choice of circumferentially averaged inlet boundary conditions, which of course are not the only way of imposing boundary conditions at the inlet. Clearly, better precision would be obtained through a coupled simulation of both the runner and draft tube, at the expense of a significantly higher computational cost. While this cost is certainly justified when the goal of the simulations is to accurately reproduce the detailed flow structures inside the draft tube, particularly at off-design conditions, this study demonstrates that circumferentially averaged conditions may prove very satisfactory when the main interest focuses on global performance characteristics of the machine.

\section{Acknowledgments}

The authors would like to acknowledge the National Science and Engineering Council of Canada (NSERC) for its support to the project CRD\#386829-09, in partnership with Andritz Hydro Ltd. The Flindt project was supported by Swiss Federal Institute of Technology, Électricité de France, Alstom, Andritz Hydro (former General Electric Canada, Sulzer Hydro and VaTech Voest Alpine MCE), Voith Hydro, Swiss Federal Commission for Technology and Innovation (PSEL) and the German Ministry of Science and Technology (BMBF).

$A_{r e f}$
$C_{\mu}$
$D_{t h}$
$k$
$L_{T}$
$H$
$N$
$n_{q}$
$Q$
$P_{s t a t}$
$r_{i n}$
$R_{t h}$
$\Delta t$

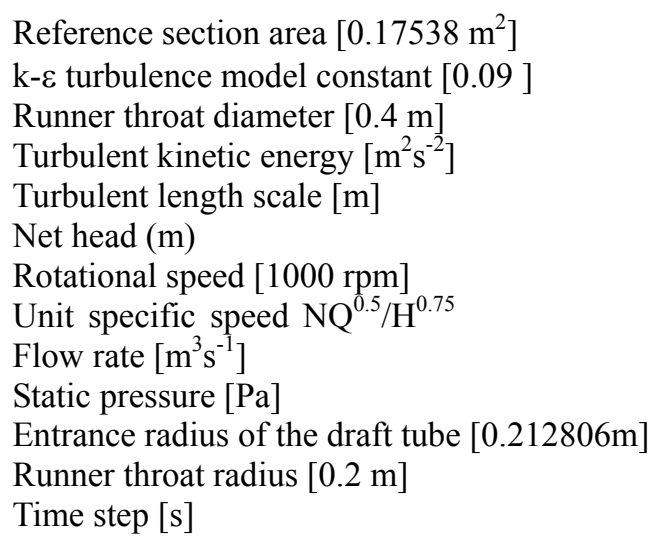

\section{Nomenclature}

$\begin{array}{ll}\text { BEP } & \text { Best Efficiency Point } \\ R A N S & \text { Reynolds Average Navier-Stokes } \\ R M S & \text { Root Mean Square } \\ \text { URANS } & \text { Unsteady Reynolds Average Navier-Stokes } \\ \chi & \text { Pressure recovery factor }=\Delta \mathrm{P}_{\text {stat }} /\left(0.5 \rho\left(\mathrm{Q} / \mathrm{A}_{\text {ref }}\right)^{2}\right) \\ \varepsilon & \text { Eddy dissipation }\left[\mathrm{m}^{2} \mathrm{~s}^{-3}\right] \\ \varphi & \text { Flow coefficient }=\mathrm{Q} /\left(\pi \omega \mathrm{R}_{\mathrm{th}}{ }^{3}\right) \\ \mu & \text { Dynamic viscosity }\left[8.899 \cdot 10^{-4} \mathrm{~Pa} . \mathrm{s}\right] \\ \rho & \text { Fluid Density }\left[997 \mathrm{~kg} \cdot \mathrm{m}^{-3}\right] \\ \varpi & \text { Angular velocity }[104.66 \mathrm{~Hz}] \\ \psi & \text { Speed coefficient }=2 \mathrm{gH} /\left(\varpi^{2} \mathrm{R}_{\mathrm{th}}{ }^{2}\right)\end{array}$

\section{References}

[1] Avellan, F., "Flow Investigation in a Francis Draft Tube: the Flindt Project," Proceedings of the 20th IAHR Symposium on Hydraulic Machinery and Systems, 2000, Charlotte, North Carolina, USA.

[2] Nilsson, H., "Evaluation of OpenFOAM for CFD of Turbulent Flow in Water Turbines," Proceedings of the 23rd IAHR Symposium on Hydraulic Machinery and Systems, 2006, Yokohama, Japan.

[3] Ruprecht, A., T. Helmrich, T. Aschenbrenner, and T. Scherer., "Simulation of vortex rope in a turbine draft tube," Proceeding of the 21st IAHR Symposium on Hydraulic Machinery and Systems, 2002, Lausanne, Switzerland.

[4] Stein, P. et al, "Numerical simulation of the cavitation draft tube vortex in a Francis turbine," Proceeding of the 23rd IAHR Symposium on Hydraulic Machinery and Systems, 2006, Yokohama, Japan

[5] Vu, T.C., F. Guibault, J. Dompierre, P. Labbé, and R. Camarero., "Computation of Fluid Flow in a Model Draft Tube Using Mesh Adaptive Techniques," Proceedings of the 20th Hydraulic Machinery and Systems, 2000, Charlotte, North Carolina, USA.

[6] Mauri, S., J.L. Kueny, and F. Avellan., "Numerical prediction of the flow in a turbine draft tube," Influence of the boundary conditions, FEDSM00, ASME Fluids Engineering, Division Summer meeting, 2000, Boston, Massachusetts, USA.

[7] Guibault, F., Y. Zhang, J. Dompierre, and T.C. Vu., "Robust and Automatic CAD-based Structured Mesh Generation for Hydraulic Turbine Component Optimization," Proceedings of the 23rd IAHR Symposium. 2006, Yokohama, Japan.

[8] Allmaras, S. and D. McCarthy., CGNS CFD Standard Interface Data Structures - Version 2.3.8. Cgns Project Group 2004 Available at: http://www.grc.nasa.gov/WWW/cgns/sids.

[9] ANSYS CFX - User Manuel, ANSYS CFX Solver, Release 12.1: Theory. 